The Hon. Secretary read a paper, contributed by Dr. Sheldon, on "A Fatal Case of Poisoning by Jeyes' Fluid "' (see page 98).

Dr. W. J. Penfold read a paper on "Mitral and Tricuspid lncompetence," and exhibited an instrument which he employed to determine the amount of valvular leakage post mortem (see page 87 ).

Previous to the business meeting, Dr. Callcott exhibited plans of the recent large additions made to the asylum, and showed members round the new buildings.

Members dined with Dr. Callcott at the asylum in the evening.

\title{
SOUTH-EASTERN DIVISION.
}

The Autumn Meeting was held at Ticehurst on Wednesday, roth October, 1900. Present : Drs. Fletcher Beach (President), Ernest White, W. J. Mickle, D. C. Thomson, H. H. Newington, J. Peeke Richards, Elliot Daunt, Robert Jones, W. R. Kingdon, C. Stanley Elliot, A. Newington, D. Bower, B. Hollănder, W. Rawes, T. Seymour Tuke, C. W. Rolleston, C. H. Johnston, J. A. Cones, Haslett, T. Newington, R. H. Cole, Alliott, and A. N. Boycott.

At I.30 p.m. luncheon was served, and at 2.30 p.m. a meeting of the Divisional Committee was held. During the afternoon the members inspected the houses and grounds of the Drs. Newingtons' establishments, and at 4.30 the meeting assembled, when Dr. Fletcher Beach (President) took the chair. The minutes of the last meeting were read and confirmed.

The following gentlemen were elected members of the Association:-Hill, James Robert, M.R.C.S.Eng., L.R.C.P.Lond., Medical Superintendent, Fenstanton, Christchurch Road, Streatham Hill ; proposed by Drs. Gardiner Hill, Boycott, and Rolleston. Hughes, Percy Theodore, M.B., Ch.M.Edin., D.P.H.Lond., Assistant Medical Officer, London County Asylum, Bexley, Kent ; proposed by Drs. Stansfield, Bond, and Lord. Kay, Alfred Reginald, M.R.C.S.Eng., L.R.C.P.Lond., Assistant Medical Officer, Middlesex County Asylum, near Tooting, S.W. ; proposed by Drs. Gardiner Hill, Boycott, and Rolleston. McConaghey, John Cunningham, M.B., Ch.B.Edin., Assistant Medical Officer, Herts County Asylum, Hill End, St. Alban's ; proposed by Drs. Moody, Boycott, and Grimmond Smith. Smith, John Salmon, M.R.C.S., L.R.C.P., Assistant Medical Officer, London County Asylum, Hanwell; proposed by Drs. Alexander, Boycott, and Grimmond Smith. Stuart, Frederick J., M.R.C.S.Eng., L.R.C.P.Lond., Assistant Medical Officer, County Asylum, Berrywood, Northampton; proposed by Drs. W. Ernest Jones, Boycott, and Grimmond Smith.

Dr. HAYES Newington intimated the receipt of a letter from Dr. LangdonDown saying that he could not be present on account of his mother's death. Dr. Newington, continuing, said that Mrs. Langdon-Down and her sons had entertained the Association most hospitably the year before last. She had made a great mark in the management of the feeble-minded. He suggested that the Secretary should express the condolence of this meeting with $\mathrm{Dr}$. Langdon-Down on his loss.

The PrEsident said that he had known Mrs. Langdon-Down and her family for many years past. She was held in the highest respect in the neighbourhood where she lived, and many were impressed by the work she had done. He concurred in the suggestion made by Dr. Newington. This was agreed to unanimously.

The Hon. Secretary mentioned that several letters and telegrams had been received from members who were unable to attend.

Dr. HAYrs Newington read a paper on "Some Incidents in the History and Practice of Ticehurst Asylum," by the Medical Superintendents (see page 62).

Dr. Brrnard Hollânder read a paper on "The Present State of Mental Science," the publication of which is postponed.

A very hearty vote of thanks was accorded to the Drs. Newington for entertaining the members of the Association; also to the President and Secretary for organising the meeting.

The members were afterwards hospitably entertained by the Drs. Newington at dinner.

XLVII. 